\title{
Cournot Competition in Networked Markets
}

KOSTAS BIMPIKIS, Stanford University

SHAYAN EHSANI, Stanford University

RAHMI ILKILIÇ, Bilkent University

The paper considers a model of competition among firms that produce a homogeneous good in a networked environment. A bipartite graph determines which subset of markets a firm can supply to. Firms compete $\grave{a}$ la Cournot and decide how to allocate their production output to the markets they are directly connected to. We assume that markets have inverse linear demand and firms have quadratic production costs. First, we show that the resulting Cournot game has a unique equilibrium for any given network and provide a characterization of the production quantities at equilibrium. Our results identify a close connection between the equilibrium outcome and supply paths in the underlying network structure. In particular, we show that whether two firms see their output in different markets as strategic substitutes or complements depends critically on the paths between those markets in the line graph induced by the original bipartite network.

Armed with a characterization of the equilibrium supply decisions, we explore the effect of changes in the network structure on firms' profits and consumer welfare. First, we study the question of a firm entering a new market. We show that entry may not be beneficial for either the firm or the consumers as such a move affects the entire vector of production quantities. The firm might face a more aggressive competition in its original markets due to its entry to a new market. Moreover, the effect on other firms and consumers also depends on their location in the network. This is in stark contrast with standard results in Cournot oligopoly where entry implies more competition in the market and thus higher consumer welfare.

Similarly, the effect of a merger between two firms on profits and overall welfare largely depends on the structure of competition in the original Cournot market. In particular, we show that insights from analyzing mergers in a single market do not carry over in a networked environment. Market concentration indices are insufficient to correctly account for the network effect of a merger and one should not restrict attention to the set of markets that the firms participating in the merger supply to.

Finally, we study the operations of a cartel including the entire set of firms. We show that the cartel maximizes its profits by appropriately segmenting the markets among its members so that a firm supplies solely to the ones allocated to it, and we provide an algorithm that computes the optimal production quantities for each firm in the cartel.

Categories and Subject Descriptors: J.4 [Social and Behavioral Science]: Economics

General Terms: Cournot competition, Horizontal Mergers, Networks, Cartels,

A full version of this paper is available at: http://stanford.edu/ shayane/files/Cournot.pdf

Authors addresses: K. Bimpikis, Graduate School of Business, Stanford University; email: kostasb@stanford.edu; S. Ehsani, Management Science and Engineering, Stanford University; email: shayane@stanford.edu; R. Ilkilic, Department of Economics, Bilkent University; email: rahmi.ilkilic@bilkent.edu.tr.

Permission to make digital or hard copies of part or all of this work for personal or classroom use is granted without fee provided that copies are not made or distributed for profit or commercial advantage, and that copies bear this notice and the full citation on the first page. Copyrights for third-party components of this work must be honored. For all other uses, contact the owner/author(s). Copyright is held by the author/owner(s).

EC'14, June 8-12, 2014, Stanford, CA, USA.

ACM 978-1-4503-2565-3/14/06.

http://dx.doi.org/10.1145/2600057.2600058 